\title{
Taiwanese Junior High School Students’ English Liquid Consonants Production
}

\author{
Ching-Ying Lin \\ National Pingtung University, Taiwan
}

\begin{abstract}
This study was to explore whether junior high school students could produce English liquid consonants well. Two purposes were explored in this study. First, explore which liquid consonants $(/ \mathbf{r} /$ or $/ / /)$ do junior high school students perform better. Second, to probe which position (word-initial, word intervocalic or word-final) of English liquid consonants $(/ \mathrm{r} /$ or $/ \mathrm{l} /$ ) do those students perform better or worse. Two research questions would be represent in this study. The sample of the study consisted of 60 junior high school students in Southern Taiwan, and they all from Grade 7th. The production tests were administered for all participants in the study. Thirty-six words in the wordlist that included $/ / /$ and $/ \mathbf{r} /$ in word-initial, word intervocalic or word-final would be used to test in this study. The results revealed that there was a significant mean difference between the $/ / /$ and $/ \mathbf{r} /$. In the word-initial $/ / /$ and $/ \mathbf{r} /$, most participants would produce those two sounds better than other positions. In word intervocalic, intervocalic /r/ would be produced better than intervocalic /l/. In word final, final $/ \mathbf{r} /$ would be produced better than final $/ 1 /$. In final $/ 1 /$, all participants in this study did not produce the final ///.The main finding indicated that the participants produced better $/ \mathbf{r} /$ than $/ \mathrm{V} /$. Pedagogical implications and suggestions for future study were showed following.
\end{abstract}

Index Terms—English liquid consonants, English production, junior high school students, word position

\section{INTRODUCTION}

In Taiwan, the pronunciation learning and teaching was ignored in educational system, even though English course has been a required course from elementary school to junior high schools in Taiwan for almost decades. Many students who have finished high school or even college education in Taiwan complain that they can't speak English and also feel afraid to speak English with native speakers although they may have spent more than ten years studying (Li, 2011). In fact, many Taiwanese speakers are unwilling to speak up because of their poor pronunciation. This is probably a result of learners' ignorance of pronunciation learning and their lack of constant or sufficient practice as well.

As far as we know, approximately 600 consonants and 200 vowels exist in the world's languages (Ladefoged, 2005, xiii). Each language contains some of the vowels and consonants in its sound system. For example, English has 24 consonants and thirteen vowels (Tsujimura, 1996). Human beings as infants initially have to learn such phonemes existing in a target language before they identify units of phonemes (i.e., words) from strings of sounds in speech. Eimas (1975) demonstrated that American English infants had higher sensitivity at the /r/-/l/ category boundary than did they within /r/ and /l/ categories. Infants are sensitive to phonetic boundaries not only in their target language but also in other languages

Language perception and production have always been considered one of the important parts of language learning. A great amount of studies have explored the relationships between perception and production in second language acquisition (e.g. Akahane \& Tohkura \&Bradlow \& Pisoni, 1996; Flege \& MacKay \& Meador, 1999; Shiri \& Peperkamp, 2013). In the acquisition of L2 production and perception, the degree of exposure and age of acquisition were important key factors (Llisterri, 1995).Pronunciation skills used to be neglected mainly due to the form of paper and pencil test adopted by the joint college entrance exam, which has encouraged the mere focus on vocabulary memorization and grammar comprehension in the English class in Taiwan. Some researches show that Taiwanese EFL learners have the difficulties in English liquids pronunciation (Chen, 2003; Hong, 2007; Li, 2011). Chen and Yang (2007) examined both proficient and less proficient Taiwanese EFL learners' pronunciation. The results showed that both groups had great difficulties on suprasegmentals. For the influence of L1 pronunciation brought the pronunciation difficulties to Taiwanese EFL learners in their L2 learning.

It is not surprising that speakers learning a second language have difficulty producing consonants that exist in the second language, but not in the sound system of their native language (Flege, 1995). Both perception and production of sounds by speakers whose languages lack the non-native contrast have been well investigated. Perhaps the best studied is the perception and production of the English $/ 1-\mathrm{r} /$ contrast by Japanese and Korean speakers (Bradlow, Pisoni, Akahane-Yamada, and Tohkura, 1997; Aoyama, Flege, Guion, Akahane-Yamada, and Yamada, 2004). It is also reasonable to expect that non-native speakers may display relatively inaccurate production of sounds even in languages that have those sounds in common, since the phonetic realizations of the shared categories may differ, despite representing the same phonological contrast. A developmental account of the problems facing adult second language learners is a useful starting point for considering the points raised above because of the potential parallels between the 
acquisition of phonetic categories in the child's first language and acquisition of nonnative phonetic categories while learning a second language in adulthood. Werker (1989) has shown that within the first year of life the infant begins to move from language universal abilities to the language-specific abilities that are characteristic of the adult. Language-universal refers to how infants are able to discriminate virtually any phonetic contrast used in a language, regardless of the environment in which they are raised, while language-specific refers to the much more restricted abilities of mature adults to discriminate or identify stimuli from phonetic categories not used in their native language. The transition from language-universal to language-specific abilities appears to be a product of the interaction between innate perceptual mechanisms and early linguistic experience (Aslin and Pisoni, 1980). Early experience serves to modify the child's perceptual system so that only those phonetic contrasts that denote differences in meaning remain distinctive.

Second language acquisition in adulthood is heavily influenced by the learner's first language (Masuda \& Arai, 2010). Learning novel speech sounds in adulthood is a unique factor of language learning because it can be profoundly impeded by neuromuscular and perceptual constraints of L1 phonology. Whereas other domains of language can be learned, memorized and practiced to attain mastery, the influence of L1 in phonology can persist for years and be resistant to change (Ioup, 2008). Since adults learning a second language often demonstrate accented speech that may limit intelligibility in the second language, the current study was undertaken to determine the effectiveness of visual feedback in speech production training of non-native phonemic contrasts. Specifically, this was explored by teaching English /1/ and /r/ to native Japanese speakers learning English as a second language in adulthood. The inclusion of visual feedback in training may aid the language learner in attaining optimal placement of the articulators for speech by making tongue positioning visible.

However, it is believed that pronunciation learning and teaching is receiving more and more attention, because the new system of multiple admissions for college has adopted more testing forms to evaluate students' English overall proficiency and learners' speaking ability is required by many colleges as well. English self-introduction, a short speech, pair work of a problem-solving task, or even an interview may be part of a speaking test. Kinnaird and Zapf (2004) mentioned that pronunciation plays an important role in people's speaking ability. A speaker who pronounces more clearly usually can be understood more efficiently when trying to express himself either in his native language or second language. Clear and accurate pronunciation may avoid occurrences of misunderstanding between speakers and listeners. It can also improve the speaker's communicating ability and gradually cultivate his self-confidence in public. According to Owolabi (2012), the findings suggested that the oral training and aural perception were ways to conquer the fear of production and perception.

Rajab (2013) identifies that raising the level of phonological awareness was a useful method in promoting EFL learners' writing and speaking abilities. In the relationship between perception and production, Flege, Bohn and Jang (1997) found that the accuracy of L2 production was affected by how L2 was perceived. Generally, language perception and production were connected to each other. The similarities between L1 and L2 caused the production errors for L2 learners, especially native language was essential in L2 production (Flege \& Bohn \& Jang, 1997; Chen \& Yang, 2007; Lin, 2011). Senel (2006) also reported that once the learners were more aware of the importance of language learning environment, they might take its opportunities as possible as they could to promote their pronunciation abilities.

In statements of the problem, the reason for choosing $/ \mathrm{r} /$ and $/ \mathrm{l} /$ in the present study is straightforward. English liquids could be troublesome to many Chinese students. English $/ \mathrm{r} /$ and $/ \mathrm{l} /$ are contrastive consonants, and there is a similar relationship in Mandarin, but no such a contrast appears in Taiwanese and many other Chinese dialects (Li, 2011.) While there are some significant studies on the learning of /l/ and /r/ by Japanese speakers and Korean speakers (Aoyamaa, Flegeb, Guionc, Yamadad, \& Yamadae, 2004; Kinnaird \& Zapf, 2004; Kusumoto, 2012; Masuda, Norrix \& Green, 2001) the studies involving Chinese EFL learners are limited. Besides, English /r/ and /l/ can occur in word-initial, word-medial and word-final positions; however, Mandarin /r/ and /l/ only occur word-initially, but not medially nor finally. Since the distribution of English /r, 1/ is wider than their Chinese equivalents, it can be predicted that many Chinese learners have difficulty pronouncing English /r/ and /1/. Based on the predicted difficulty and the some Asian research studies, and Chinese subjects' performance in liquids is chosen as the focus of this study.

The purpose of the study was to explore whether junior high school students could produce English liquid consonants well. Two purposes were explored in this study. First, to explore what liquid consonants (/r/ or /l/) do junior high school students perform better. Second, to probe which position (word-initial, word intervocalic or word-final) of English liquid consonants $(/ \mathrm{r} /$ or $/ \mathrm{l} /)$ do those students perform better or worse.

In research questions, more specifically, the present study attempted to answer the following questions. First, which liquid consonants (/r/ or /1/) do junior high school students perform better? Second, which position (word-initial, word intervocalic or word-final) of English liquid consonants (/r/ or $/ \mathrm{l} /$ ) do those students perform better or worse?

\section{LITERATURE REVIEW}

\section{A. English Production in Liquid Sound}

Based on the English four skills, Bozorgian (2012) found the EFL learners had low proficiency in the listening and speaking. Over the past two decades, English liquid perception and production have been widely examined. Particularly, several studies have explored them with EFL learners (Masuda \& Norrix \& Green, 2001; Hsieh, 2007; Kusumoto, 
2012). In Masuda, Norrix, and Green (2001) studies, they examined the perception and production of English /r/-/l/ among 5 Japanese native speakers. Regarding this study, 5 Japanese native speakers completed two production tests, two perception tests and a word familiarity task. They explored development of perception and production skills of Japanese learners of English over a study period of six months. First, they observed that for student's production improved greatly but only small changes in perception were noted. This suggests that perception and production skills of JLE can develop at different rates. Second, phonological environments are crucial for both perception and production in different manners. The results revealed that the position of $/ \mathrm{r} /$ and $/ \mathrm{l} /$ in a word influenced Japanese native speakers to identify the sounds, and they reported that final /l/ and /r/ were easier to distinguish than other positions for Japanese native speakers. The participants demonstrated initial /// and initial consonant cluster /r/ were more difficult to identify than other positions. They also had difficulties on producing final/1/ and initial consonant cluster /1/, but they produced initial consonant cluster /r/ and final /r/ easily. In Kusumoto (2012) study, between perception and production: Is the ability to hear L1-L2 sound differences related to the ability to pronounce the same sounds accurately, the researcher explored thirty-eight native speakers of Japanese to perceive and produce the English /r/-/l/ contrast. The researcher also mentioned that most of the participants who could distinguish /r/-/l/ contrast were also able to distinguish other sound contrasts. All other participants performed better on the other consonant contrasts perception test. The position of $/ \mathrm{r} /$ and $/ \mathrm{l} /$ in a word has an effect on the ease of identification of these sounds for the Japanese participants. The participants also indicated that final $/ \mathrm{r} /$ and final $/ \mathrm{l} /$ in perception and initial $/ \mathrm{l} /$ and final $/ \mathrm{r} /$ in the production were easier to perceive and produce, but final consonant cluster $/ \mathrm{l} /$ and $/ \mathrm{r} /$ in perception and final consonant cluster $/ \mathrm{r} /$ and intervocalic /r/ in production were more difficulties to perceive and produce. In Kinnaird and Zapf (2004) studies, an acoustical analysis of a Japanese speaker's production of English $/ \mathrm{r} /$ and $/ \mathrm{l} /$, In general, native Japanese speakers have difficulty perceiving the English /r/ and /l/ phonemes due to the fact their native language does not have these two sounds as contrasting phonemes. Although much has been written on L1 Japanese with regards to the English /1/ and /r/, little has addressed the acoustical differences between speakers of Japanese and speakers of English as they produce the English liquids. Hong (2007) examined the English consonant clusters perception and production in Taiwanese EFL learners. Hong noticed that the learners who had good production abilities, also performed well in perception. And he suggested that the learners who were more exposed to English might promote their perception and production skills.

\section{B. English Liquid Sound in Different Position}

In Masuda, Norrix, and Green (2001) studies, development of speech perception and production skills of /r/ and /l/ in Japanese learners of English, they mentioned that /l/ in word final position was easiest to perceive, while difficult to produce. Third, the word positions that showed the greatest improvements in production (i.e. intervocalic /1/ and consonant cluster /l/) were different from those that showed the greatest improvement in perception (i.e. intervocalic /r/, initial $/ 1 /$, and consonant cluster $/ \mathrm{r} /$ ). This suggests that perception and production of the liquids in various word positions develop at different rates. In addition, the position of $/ \mathrm{r} /$ and $/ \mathrm{l} / \mathrm{in}$ a word had a large effect on successful production and perception of these sounds over the study period of six months. In Kusumoto (2012) study, between perception and production: Is the ability to hear L1-L2 sound differences related to the ability to pronounce the same sounds accurately, the researcher mentioned that final $/ \mathrm{r} /$, final $/ \mathrm{l} /$, and initial $/ \mathrm{r} /$ are easier for Japanese learners of English to perceive. The initial /l/ was relatively difficult for the students. Also, final consonant-cluster /r/ and final consonant-cluster /1/ were very difficult for the students. The bright /l/ exhibits a higher degree of difficulty of identification than dark /1/. In Kinnaird and Zapf (2004) studies, an acoustical analysis of a Japanese speaker's production of English /r/ and /l/, the study found substantial differences between the F3 values for /1/ in every word position, and smaller differences between the F2 values of /1/ and the F3 values for /r/. This evidence provides support for the idea that perception and production may be closely linked and, thus, calls for most acoustical analysis of the productions of native Japanese speakers.

\section{Methodology}

For subjects, the sample of the study consisted of 60 junior high school students in Southern Taiwan, and they all from Grade 7 th. Fifteen students among them were randomly chosen to take part in the study. Of these fifteen students whose average age was twelve, 28 were male and 32 were female.

For the instruments, the production tests were administered for all participants in the study. Thirty-six words in the wordlist that included / $/$ / and /r/ in word-initial, word intervocalic or word-final would be used to test in this study. Each part included twelve words (/1/ had six words and /r/ had sic words.) Assessment would also be used to check student's production during the test in this study.

The procedure, the first section in the procedure was to decide what words would be used to test and assigning participants randomly were required. Before production test, researcher would talk about the testing rule to participants, and each student would be tested 10 minutes. During the test, all the interviews were recorded by a smart phone. The procedures would be represented in Table 1. 
TABLE 1

DATA COLLECTION PROCEDURES

\begin{tabular}{|l|l|l|}
\hline Step & Data Collection & Time \\
\hline 1 & Deciding what words would be used to test & \\
\hline 2 & Assigning participants randomly & \\
\hline 3 & Talking about the testing rule & \\
\hline 4 & Conducting the production test & 10 minute/ one student \\
\hline 5 & Data analysis & \\
\hline
\end{tabular}

The data analysis, after collected the data, the researcher categorized, tabulated, and recombined the data. IBM SPSS (20) would be used to analyze the data by pair t-test to get the each mean, standard deviation and t value. The researcher would also explain the result, and then made the conclusion and suggestion.

\section{Results}

In order to determine the performance on producing liquid consonants, a paired sample t-test was administered at a selected probability level $(\alpha<.05)$. The data in Table 2 showed that the production test scores means of $/ 1 /(\mathrm{M}=6.80)$ was lower than means of $/ \mathrm{r} /(\mathrm{M}=12.0)$. A statistical significant difference between $/ \mathrm{l} /$ and $/ \mathrm{r} /$ was inspected $(\mathrm{t}(59)=$ $-14.46, \mathrm{p}=0<.05)$. The results indicated that $/ \mathrm{l} /$ was more difficult to produce than $/ \mathrm{r} /$ for Taiwanese junior high school students.

TABLE 2

The PAIR T-Test For Two Liquid CONSONANTs (/r/ AND /l/) PRODUCTION OF JUNIOR High SCHOOL STUDENTS (N=60)

\begin{tabular}{|l|l|l|l|l|l|l|}
\hline Liquid Sound & Mean & SD & Pair Mean & Pair SD & T value & Sig. \\
\hline$/ 1 /$ & 6.80 & 1.29 & \multirow{2}{*}{-5.20} & 2.79 & -14.46 & \multirow{2}{*}{$0 *$} \\
\hline /r/ & 12.0 & 3.31 & Note. *T-test <.05 \\
\hline
\end{tabular}

In order to examine the performance on word position (word-initial, word intervocalic or word-final) of English liquid consonants $(/ \mathrm{r} /$ or $/ \mathrm{l} /)$ a paired sample t-test was also administered at a selected probability level $(\alpha<.05)$. From the statistical data described in Table 3, 4 and 5, initial /l/ and /r/ were performed better than other positions. Mean of /1/ in each position were 5.33 (initial), 1.47 (intervocalic) and 0 (final), and mean of $/ \mathrm{r} / \mathrm{in}$ each position were 5.53 (initial), 2.47 (intervocalic) and 3.93 (final). In the /1/ production, initial /1/ is performed best than other two positions and final /// is performed worst. In the $/ \mathrm{r} /$ production, initial $/ \mathrm{r} /$ is also performed best than other two positions. Overall, initial /r/ is performed best than other positions by junior high students in this study, and final $/ 1 /$ is performed worst in this study. Among them, statistical significant difference between word-final $/ \mathrm{l} / \mathrm{and} / \mathrm{r} / \mathrm{was}$ inspected $(\mathrm{t}(59)=-18.75, \mathrm{p}=0<.05)$. And the other position's performances did not have significant difference.

TABLE 3

THE PAIR T-TEST FOR Two LIQUID CONSONANTS (/r/ AND /l/) IN WORD-INITIAL PRODUCTION OF JUNIOR High SCHOOL STUDENTS (N=60)

\begin{tabular}{|l|l|l|l|l|l|l|}
\hline Liquid Sound & Mean & SD & Pair Mean & Pair SD & T value & Sig. \\
\hline$/ 1 /$ & 5.33 & 1.31 & \multirow{2}{*}{-0.20} & 1.23 & -1.26 & \multirow{2}{*}{$0.21 *$} \\
\hline$/ \mathrm{r} /$ & 5.53 & 0.81 & Note. *T-test <.05 \\
\hline
\end{tabular}

TABLE 4

THE PAIR T-TEST FOR Two LiQuid CONSONANTS (/r/ AND /l/) IN WORD INTERVOCALIC PRODUCTION OF JUNIOR HiGH SCHOOL STUDENTS (N=60)

\begin{tabular}{|l|l|l|l|l|l|l|}
\hline Liquid Sound & Mean & SD & Pair Mean & Pair SD & T value & Sig. \\
\hline$/ 1 /$ & 1.47 & 0.50 & -1.00 & 1.88 & -4.13 & \multirow{2}{*}{$0.00 *$} \\
\hline$/ \mathrm{r} /$ & 2.47 & 1.87 & Note. *T-test <.05 & & \\
\hline \multicolumn{7}{|c|}{} \\
\hline
\end{tabular}

TABLE 5

THE PAIR T-Test FOR Two LiQuid CONSONANTS (/r/ AND/1/) IN WORD-FinAL PRODUCTION OF JUNIOR HiGH SCHOOL STUDENTS (N=60)

\begin{tabular}{|l|l|l|l|l|l|l|}
\hline Liquid Sound & Mean & SD & Pair Mean & Pair SD & T value & Sig. \\
\hline$/ 1 /$ & 0 & 0 & \multirow{2}{*}{ Note. *T-test <.05 } & 1.63 & -18.75 & \multirow{2}{*}{$0^{*}$} \\
\hline$/ \mathrm{r} /$ & 3.93 & 1.62 & & \\
\hline
\end{tabular}

\section{CONCLUSION}

\section{A. Performance on English Liquid Sounds}

The study sought to detect the different performance in producing liquid sounds $/ \mathrm{l} / \mathrm{and} / \mathrm{r} /$. The results revealed that there was a significant mean difference between the $/ \mathrm{l} /$ and $/ \mathrm{r} /$. Such findings indicated that the participants produced better $/ \mathrm{r} /$ than $/ \mathrm{l} /$. The reason why students could produce $/ \mathrm{r} /$ than $/ \mathrm{l} /$ may focus on different positions. Generally speaking, participants' performances in $/ \mathrm{r} /$ are better than the $/ 1 /$.

English Liquid Sounds Production in Different Positions, in this section, there were three different positions in the 
production test. In the word-initial $/ 1 /$ and $/ \mathrm{r} /$, most participants would produce those two sounds better than other positions, but only few students in producing initial /r/ would substitute for $/ 1 /$ sound. In Taiwan, many students did not emphasize retroflex, for example: the word "row" that would be substituted /1/ and became "low".

In word intervocalic, intervocalic /r/ would be produced better than intervocalic $/ 1 /$. In intervocalic $/ 1 /$, most students would substitute for $/ \mathrm{o} /$ and /o/ sounds. For example, the words "cold /kold/", "hold / hold/" and "told /told/" would become "/kod/", "/hod/", and "/tod/". In intervocalic /r/, most students could produce that correctly, but few students would omit intervocalic /r/ when they produced the word had intervocalic /r/. For example, the words "dark/dark/" and "mark /mark/" would become "/dak/", and "/mak/".

In word final, final /r/ would be produced better than final /l/. In final /l/, all participants in this study did not produce the final /1/. Some students could not produce dark [1] sound, and some students omitted final /1/ directly. In final /r/, most students could also produce that correctly, but few students would omit final $/ \mathrm{r} /$ when they produced the word final /r/. For example, the words "car /kar/", "mar/mar/" and "far /far/" would become "/ka/", "/ma/", and "/fa/".

The researcher also found that if /r/ in vowel sound /a/ back, students would omit /r/ sound and produce directly, not only in word intervocalic but in word final.

\section{B. Pedagogical Implications}

From the study, pedagogical implications would be provided. According this study, it found that students could produce the /r/ than /1/ sounds. Teacher should teach students how to pronounce the KK correctly, and give students more time to do the practice in pronunciation. In recent years, most students who can read and understand KK phonetic are in cram to learn KK phonetic. Because in school, the teacher did not have extra time to focus on KK phonetics teaching, only some students who go to cram school have a little extra time to learn KK phonetic. This situation caused most of the junior high school students still do not understand and read KK phonetic. Students also should learn KK phonetic by themselves. English teachers should provide more opportunities in pronunciation practice to vocational high school students, so this may bring benefits to raise the students' perception and production skills. Future research may explore whether English proficiency influences learners' English liquid perception and production.

\section{Suggestions for Future Studies}

Although an equal number of males and females participated in the present experiment, we did not include gender as a possible factor influencing accurate pronunciation of English /r/ and /1/. It would be of interest to regard gender as a variable in future researches to investigate whether males or females have better performance in liquids. Moreover, the subjects recruited in our study are all encouraging volunteers. Therefore, factors of their overall English proficiency and motivation of improving pronunciation skills are not well-controlled. More researches can be conducted to examine if students with better English proficiency produce more accurate /r/ and /1/, or those with high motivation perform better.

Lastly, due to most of the subjects' inability in expressing themselves orally in English, only reading out task is designed in the present experiment, other methods as an interview or free conversation is not involved. Hence, it is less possible to elicit students' pronunciation in a more spontaneous and communicative situation. For example, the method of "answering questions" in oral tests applied by GEPT (General English Proficiency Test) may be a good choice to explore students' erroneous production of liquids elicited naturally and communicatively. Future researches in this area are expected to adopt a more natural and communicative method to evaluate Chinese students' mispronunciation in liquids. Students' ability in distinguishing /r/ from $/ 1 /$ in different word positions can also be explored to examine their performance in liquid perception. Perhaps future research also could examine more deeply the different performances of perception and production tasks on vocational and academic high school students. There is a clear need to explore the role of L1 and its impact on L2 production. An investigation into the link between perception and production is certain to bring the light on the issues to be more close to the details in these two factors.

\section{REFERENCES}

[1] Akahane-Yamada, R., Tohkura, Y., Bradlow, A. R., \& Pisoni, D. B. (1996). Does training in speech perception modify speech production? Proceedings of the Fourth International Conference on Spoken Language Processing, 2, 606-609.

[2] Aoyamaa, K., Flegeb, J., E., Guionc, S. G., Yamadad, R., K., \& Yamadae, T. (2004). Perceived phonetic dissimilarity and L2 speech learning: the case of Japanese /r/ and English /1/ and /r/. Journal of Phonetics, 32, 233-250.

[3] Aslin, R.; Pisoni, D. (1980). Some developmental processes in speech perception. In: Yeni-Komshian, G.; Kavanagh, J.; Ferguson, C., editors. Child Phonology Perception and Production. Academic New York, 67-96.

[4] Bradlow, A., D. B. Pisoni, R. Akahane-Yamada, and Y. Tohkura. (1997). Training Japanese listeners to identify English /r/ and /l/: IV. Some effects of perceptual learning on speech production. The Journal of the Acoustical Society of America, 101(4), 2299-2310.

[5] Chen, H. J. (2003). A study of Chinese students' pronunciation problems in English liquids. Master's thesis, National Taiwan Normal University, Taipei, Taiwan.

[6] Chen, S. C., \& Yang, M. N. (2007). Effect of proficiency on Taiwanese EFL learners' pronunciation. Retrieved 2007, from Samara AltLinguo E-Journal: http://samaraaltlinguo.narod.ru/ejournal/207_chen_yang_2.pdf

[7] Eimas, P. D. (1975). "Auditory and phonetic coding of the cues for speech: Discrimination of the [r-l] distinction by young infants," Perception and Psychophysics, 18, 341-347.

[8] Flege, J.E. (1995). Second-language speech learning: theory, findings, and problems. In W. Strange (Ed.) Speech Perception 
and Linguistic Experience: Issues in Cross-Language Research, 233-272. Timonium MD: York.

[9] Flege, J. E., Bohn, O. S., \& Jang, S. (1997). Effects of experience on non-native speakers's production and perception of English vowels. Journal of Phonetics, 25, 437-470.

[10] Flege, J. E., MacKay, L. R. A., \& Meador, D. (1999). Native Italian speakers' perception and production of English vowels. Acoustical Society of America, 106 (5), 2973-2987.

[11] Hsieh, Y. N. (2007). Perceptual relation among English /r/-/l/ contrast and Mandarin ////l/contrast for Mandarin and Taiwanese southern min bilingual children. Master's thesis, National Cheng Kung University, Hsin Chu, Taiwan.

[12] Hong, J. Q. (2007). Perceptual and production studies on English consonant clusters by Taiwan Mandarin speakers. Master's thesis, National Cheng Kung University, Hsin Chu, Taiwan.

[13] Kinnaird, S., K. \& Zapf, J. (2004). An acoustical analysis of a Japanese speaker's production of English /r/ and /1/. Master's thesis, Indiana University, Bloomington, United State.

[14] Kusumoto, Y. (2012). Between perception and production: Is the ability to hear L1-L2 sound differences related to the ability to pronounce the same sounds accurately? Journal of Polyglossia, 22, 15-33.

[15] Ladefoged, P. (2005). Vowels and consonants: An introduction to the sounds of language. Blackwell, Oxford, UK.

[16] Li, C., Y. (2011). Liquid acquisition by Taiwanese EFL leaners. Master's thesis, National Kaohsiung Normal University, Kaohsiung, Taiwan.

[17] Long, M. (1990). Maturational constraints on language development. Studies in Second Language Acquisition, 12(3), $251-285$.

[18] Masuda, H., \& Arai, T. (2010). Processing of consonant clusters by Japanese native speakers: Influence of English learning backgrounds. Acoustical Science and Technology, 31(5), 320-327.

[19] Masuda, K.,Norrix, L., \& Green, K. (2001). Development of speech perception and production skills of /r/ and /l/ in Japanese learners of English. Arizona Working Papers in Second Language Acquisition and Teaching (SLAT), 8, 56-68.

[20] Rajab, H. (2013). Developing speaking and writing skills of L1 Arabic EFL learners through teaching of IPA phonetic codes. Theory and Practice in Language Studies, 3(4), 653-659.

[21] Senel, M. (2006). Suggestions for beautify the pronunciation of EFL learners in Turkey. Journal of Language and Linguistic Studies, 2(1), 111-125.

[22] Shiri, L. A., \& Peperkamp, S. (2013). Low inhibitory skill leads to non-native perception and production in bilinguals' native language. Journal of Phonetics, 41, 320-331.

[23] Smith, J., G. (2010). Acoustic properties of English /l/ and /r/ produced by mandarin Chinese speakers. Master's thesis, University of Toronto, Toronto, Canada.

[24] Tsujimura, N. (1996). An introduction to Japanese linguistics. Blackwell, Oxford, UK.

[25] Owolabi, D. (2012). Production and perception problems of English dental fricatives by Yoruba speakers of English as a second language. Theory and Practice in Language Studies, 2(6), 1108-1113.

[26] Werker J. (1989). Becoming a native listener. Am Sci, 77:54-59.

Ching-Ying Lin is an assistant professor and the director of international cooperation section at National Pingtung University. She received her Ed.D. in Bilingual Education at Texas A\&M University, U.S.A. She was also the visiting professor at Gonzaga University and visiting scholar at Chattanooga State Community College, U.S.A. Her specialty is TESOL/TEFL Methodology, Speech and Communication, Second Language Acquisition, Learning Strategy, TESOL/ TEFL Curriculum and Material Design. 